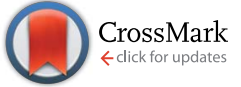

Cite this: RSC Adv., 2017, 7, 15096

Received 11th January 2017

Accepted 27th February 2017

DOI: $10.1039 / c 7 r a 00446 j$

rsc.li/rsc-advances

\section{Mesopore-dominant wormhole-like carbon with high supercapacitive performance in organic electrolyte $\uparrow$}

\author{
Xiaoqing Yang, ${ }^{*}$ Jianlin Yu, Weijian Zhang and Guoqing Zhang \\ For designing porous carbon-based electrodes in electric double-layer capacitors (EDLCs), it is crucial to \\ construct a large ion-accessible surface area as well as efficient mass transfer pathways, especially for \\ organic electrolytes with large ion sizes. Here we report the supercapacitive properties of wormhole-like \\ mesoporous carbon (WMC) in both $6 \mathrm{M} \mathrm{KOH}$ and $1 \mathrm{M}$ tetraethylammonium tetrafluoroborate $\left(\mathrm{TEABF}_{4}\right)$ \\ electrolyte. The suitable mesopore size $(3.1 \mathrm{~nm})$ of WMC, which is 3 times larger than the solvated ion \\ size of $\mathrm{TEABF}_{4}$, offers a large ion-accessible surface area for charge accumulation. The 3D continuous \\ carbon framework and interconnected mesopore-dominant structure endow the WMC with excellent \\ electron/electrolyte transfer pathways. As a consequence, it presents a small decrease of specific mass \\ capacitance in $\mathrm{TEABF}_{4}$ as compared to that in $\mathrm{KOH}$ (174 vs. $189 \mathrm{~F} \mathrm{~g}^{-1}$, respectively), and a far superior \\ high-rate capability in $\mathrm{TEABF}_{4}$ than most of other porous carbon materials.
}

\section{Introduction}

Nanoporous carbon materials (PCMs) have sparked enormous interest as the electrode of electric double-layer capacitors (EDLCs), not only in fundamental scientific investigations, but also for practical applications. ${ }^{\mathbf{1 - 1 4}}$ Their low cost, long cycling stability and stable physical-chemical properties make them more applicable as compared to the other candidates, such as conducting polymers and transition metal oxides. ${ }^{4-12}$ Commercially available activated carbon (AC) is widely used as electrodes in practical applications. To meet the ever-increasing demands of high energy density and high rate charging-discharging properties, numerous efforts have been devoted to developing novel PCMs with well-defined nanostructures for optimizing the electrochemical capacitive behaviors..$^{5-26}$

Although the energy storage mechanism of EDLCs is still unclear, guidance based on abundant previous investigations for designing the nanostructure of PCM is generally accepted: constructing a large surface area coupled with sufficient electrolyte transfer pathways, such as microporous carbons with a tunnel shaped macroporous structure, ${ }^{15}$ nitrogen-containing ultramicroporous carbon nanospheres, ${ }^{\mathbf{1 6}}$ hierarchical porous carbon, ${ }^{17-20}$ hollow carbon nanospheres with ultrahigh surface area, ${ }^{21}$ etc. $^{22-27}$

However, a large surface area is usually contributed by a developed microporosity (with abundant pores $<2 \mathrm{~nm}$ ), ${ }^{15-21}$

School of Materials and Energy, Guangdong University of Technology, Guangzhou 510006, PR China. E-mail: yxq-886@163.com

$\dagger$ Electronic supplementary information (ESI) available. See DOI: $10.1039 / \mathrm{c} 7 \mathrm{ra00446j}$ while in practical application, organic electrolyte of tetraethylammonium tetrafluoroborate $\left(\mathrm{TEABF}_{4}\right)$ rather than aqueous electrolytes (e.g., $\mathrm{KOH}$ and $\mathrm{H}_{2} \mathrm{SO}_{4}$ ) is used because of its much higher working potential. Thus, a problem is encountered for most PCM-based electrodes: the ion-accessible surface area would be reduced to a great extent because the ion size of $\mathrm{TEA}^{+}$ and $\mathrm{BF}_{4}{ }^{-}$is much larger than that of $\mathrm{K}^{+}, \mathrm{OH}^{-}$and $\mathrm{SO}_{4}{ }^{-}$, etc. (ca. $0.6 \mathrm{~nm} v s$. ca. $0.3 \mathrm{~nm}$, Table $\mathrm{S} 1 \dagger){ }^{28}$ resulting in a much lower specific mass capacitance $\left(C_{\mathrm{m}}\right)$ in almost all of the studies, ${ }^{29-34}$ e.g., $294 \mathrm{~F} \mathrm{~g}^{-1}$ in $6 \mathrm{M} \mathrm{KOH} \mathrm{vs.} 129 \mathrm{~F} \mathrm{~g}^{-1}$ in $1 \mathrm{M} \mathrm{TEABF}_{4},{ }^{29} 210 \mathrm{~F}$ $\mathrm{g}^{-1}$ in $6 \mathrm{M} \mathrm{KOH}$ vs. $103 \mathrm{~F} \mathrm{~g}^{-1}$ in $1 \mathrm{M} \mathrm{TEABF}_{4},{ }^{30} 305 \mathrm{~F} \mathrm{~g}^{-1}$ in $6 \mathrm{M}$ $\mathrm{KOH}$ vs. $178 \mathrm{~F} \mathrm{~g} \mathrm{~g}^{-1} 1 \mathrm{M} \mathrm{TEABF}_{4} \cdot{ }^{31}$ What's worse, it should be noted that the size of the solvated $\mathrm{TEA}^{+}$and $\mathrm{BF}_{4}^{-}$(ca. $1.2 \mathrm{~nm}$, Table S1 $\dagger$ ) is even two times larger than that of the desolvated ones. ${ }^{28}$ This may lead to a more serious decrease of $C_{\mathrm{m}}$ at high current densities owing to the insufficient time of solvent shell removing, ${ }^{28}$ ion diffusion and charge arrangement ${ }^{35,36}$ during a limited charge/discharge period. For instance, a pistachionutshell-based PCM with a high surface area of $1069 \mathrm{~m}^{2} \mathrm{~g}^{-1}$ and micropore proportion $\left(V_{\text {mic }} \%\right.$ ) of $83 \%$ presented $C_{\mathrm{m}}$ of 313 and $215 \mathrm{~F} \mathrm{~g}^{-1}$ in aqueous and organic electrolyte, respectively. When the scan rate was increased from 2 to $500 \mathrm{mV} \mathrm{s}^{-1}$, a much lower $C_{\mathrm{m}}$ retention was observed in organic electrolyte than that in aqueous electrolyte ( $\sim 25 \%$ vs. 68\%). ${ }^{34}$ Therefore, considering that aimlessly increasing the pore size will lead to a decrease of the surface area, the crucial point for designing the state-of-theart PCM-based electrode in practical application is to construct a suitable pore size for simultaneously achieving a large ionaccessible surface area for charge accumulation and guaranteeing the transfer of the electrolyte, particularly under high current densities. 
Among various novel PCMs, wormhole-like mesoporous carbon (WMC) is expected to demonstrate great potential for organic-electrolyte-based EDLCs, because it presents not only a high surface area primarily contributed by small mesopores, but also a unique 3D continuous mesopore morphology and carbon skeleton. ${ }^{37}$ We have so far pioneered the fabrication of WMC with widely tunable mesopore sizes through a simple onestep-templating technique. ${ }^{37}$ This successful fabrication offers us the possibility to construct WMCs with a suitable pore size and high surface area for EDLC application.

Therefore, in this work, for the first time, we adopt WMCs with different mesopore diameters and surface area as the electrode materials of $\mathrm{TEABF}_{4}$-based EDLCs. It is highlighted that the suitable size of the small mesopores $(3.1 \mathrm{~nm})$ offers a large ion-accessible surface area for charge accumulation and an effective electrolyte transfer pathway, even under high current densities. As a result, it presents little decrease of $C_{\mathrm{m}}$ in $\mathrm{TEABF}_{4}$ in contrast to that in aqueous electrolyte $(174 v s .189 \mathrm{~F}$ $\mathrm{g}^{-1}$ ). In addition, WMC demonstrates a much more superior high-rate capability in organic electrolyte than most of other PCMs.

\section{Experimental}

\subsection{Preparation of WMCs}

The WMCs were prepared by a silica template method according to the previous report. ${ }^{37}$ During a typical procedure, sucrose was dissolved in an aqueous sulfuric acid solution $(\mathrm{pH}=2.0)$ under stirring, followed by adding tetraethyl orthosilicate (TEOS) with and without $4 \mathrm{wt} \% \mathrm{HF}$ solution under stirring (sucrose : $\mathrm{H}_{2} \mathrm{SO}_{4}$ solution : TEOS $=2 \mathrm{~g}: 3$ $\mathrm{mL}: 4 \mathrm{~mL}$ ). The obtained homogeneous mixture was quickly gelated and aged at $40{ }^{\circ} \mathrm{C}$ for 2 days, and then further reacted for $6 \mathrm{~h}$ at $160{ }^{\circ} \mathrm{C}$. Subsequently, these samples were carbonized at $900{ }^{\circ} \mathrm{C}$ for 3 hours in $\mathrm{N}_{2}$ flow with a heating rate of $4{ }^{\circ} \mathrm{C}$ $\mathrm{min}^{-1}$. After carbonization, the resulting carbon/silica composites were washed with $40 \mathrm{wt} \% \mathrm{HF}$ solution to remove the silica, followed by filtration and drying. The obtained WMCs with and without adding HF during the sol-gel process were denoted as WMC7 (TEOS/HF ratio $=7$ ) and $\mathrm{WMC0}$, respectively.

\subsection{Structure characterization}

Raman spectra were conducted on a Renishaw inVia Laser Micro-Raman spectrometer. X-ray diffraction (XRD) patterns of the WMC samples were collected using a diffractometer equipped with a $\mathrm{Cu} \mathrm{K} \alpha$ source by D/MAX 2200 VPC equipment. The microstructure of the WMCs was investigated by a transmission electron microscope (TEM, JEOL JEM-2010) and a Micromeritics ASAP 2010 analyzer at $77 \mathrm{~K}$. The BET method was utilized to calculate the $S_{\mathrm{BET}}$ using adsorption data in a relative pressure range from 0.05 to 0.21 . The total pore volume $\left(V_{\text {total }}\right)$ was estimated from the amount adsorbed at a relative pressure $\left(P / P_{0}\right)$ of 0.990 . Density functional theory (DFT) was used to analyze the pore size distribution and cumulative pore volume.

\subsection{Electrochemical measurement}

A composite comprising the WMCs, poly(vinylidene difluoride) and acetylene black (mass ratio of $8: 1: 1$ ) was uniformly pressed onto the current collector of nickel foam or aluminum foil. After drying in vacuum at $120^{\circ} \mathrm{C}$ for over $8 \mathrm{~h}$, the electrode was used as the working electrode. The electrochemical performance was measured in both aqueous electrolyte of $6 \mathrm{M}$ $\mathrm{KOH}$ and organic electrolyte of $1 \mathrm{M} \mathrm{TEABF} / \mathrm{polypropylene}_{4}$ carbonate (PC) using a sandwich-type coin EDLC. Galvanostatic charge-discharge (GCD) tests were performed at different current densities from 0.1 to $10 \mathrm{~A} \mathrm{~g}^{-1}$ using a Neware Battery Program-control Test System (CT30008W). Electrochemical impedance spectroscopy (EIS, excitation signal: $5 \mathrm{mV}$ and frequency range: $0.001-100000 \mathrm{~Hz}$ ) and cyclic voltammetry (CV) at a scan rate of $100 \mathrm{mV} \mathrm{s}^{-1}$ were carried out using a CHI660E electrochemical workstation with the same cell. The $C_{\mathrm{m}}$ (in $\mathrm{F}^{-1}$ ) of the samples was calculated by the formula of $C_{\mathrm{m}}=\frac{I \times \Delta t}{\Delta U} \times \frac{m_{1}+m_{2}}{m_{1} \times m_{2}}$, where $I$ was the discharge current; $\Delta t$ was the discharge time; $\Delta U$ was the potential change in discharge; $m_{1}$ and $m_{2}$ were the mass of the positive and negative active electrode materials, respectively. At the same time, a commercial AC from Kuraray Chemical Co., Ltd. for supercapacitors was tested and served as a reference.

\section{Results and discussion}

As shown in Fig. 1a, the XRD patterns of both the WMC samples exhibit two peaks around $24^{\circ}$ and $44^{\circ}(2 \theta)$, which correspond to the (002) and (101) diffraction of hexagonal graphite based on the JCPDS Card No. 04-0850, respectively. The relatively broader peaks and larger $d$-spacings between (002) planes (3.7 $\AA$ ) in comparison to those of graphite (3.4 $\AA$ ) imply a low graphitization degree of the WMCs. ${ }^{38}$ Meanwhile, two peaks around $1350 \mathrm{~cm}^{-1}$ (D-band) and $1590 \mathrm{~cm}^{-1}$ (G-band) of both WMC samples are clearly observed in the Raman spectra (Fig. 1b). The D-band is attributed to the disordered structures of carbon, and the G-band corresponds to an ideal graphitic lattice vibration mode with $\mathrm{E}_{2 \mathrm{~g}}$ symmetry. ${ }^{39}$ The relatively higher intensity ratio of $\mathrm{D} / \mathrm{G}$ bands $\left(I_{\mathrm{D}} / I_{\mathrm{G}}\right)$ confirms that the WMCs are amorphous carbons with a low graphitization degree. ${ }^{39}$

Fig. 2 shows the TEM images of the WMC samples. Apparently, both samples show a continuous carbon framework with a number of interconnected mesopores. After adding HF, the mesopore size of WMC7 is obviously increased due to the catalyzed effect of $\mathrm{F}^{-}$in the gelation process of TEOS. ${ }^{37,40}$ In brief, with the existence of $\mathrm{F}^{-}$, the size of the resulting sol particles will increase correspondingly in order to overcome the repulsive effect of surface charges built up on the $\mathrm{F}^{-}$-containing particulate clusters. In consequence, the radial dimension of the silica framework in carbon/silica composite is increased, leading to a larger mesopore size of the WMC7 after template removing.

$\mathrm{N}_{2}$ adsorption-desorption isotherms were performed to confirm the developed mesoporous structure quantitatively (Fig. 3a). Both of the two WMC samples show obvious uptakes at 

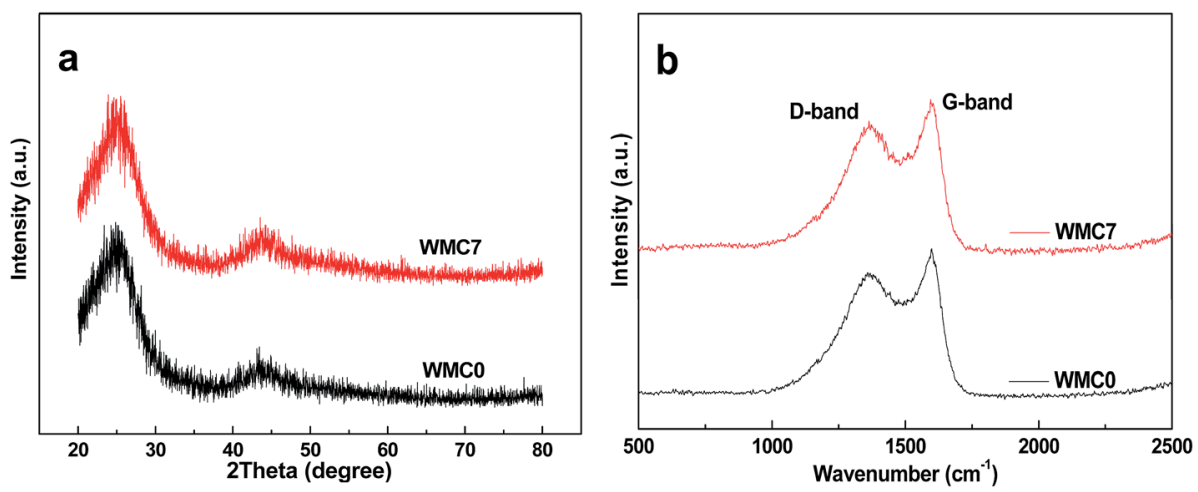

Fig. 1 (a) XRD patterns and (b) Raman spectra of the WMCs.
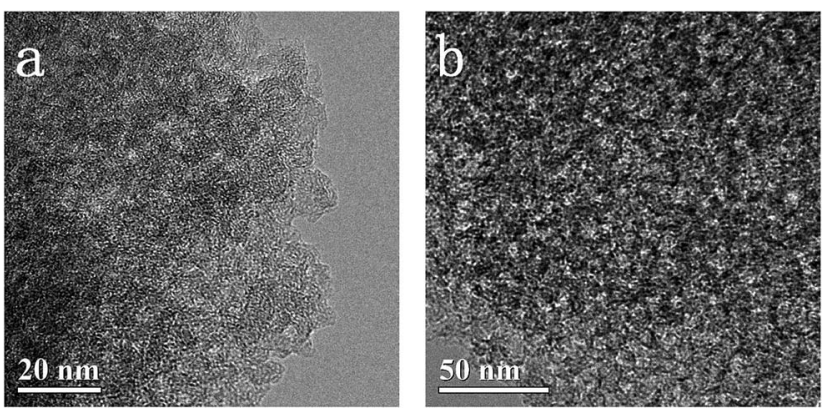

Fig. 2 TEM images of the (a) WMCO and (b) WMC7 samples.

the medium $P / P_{0}$, implying that they are typical mesoporous materials. ${ }^{13}$ The uptake of WMC7 at relatively higher $P / P_{0}$ in comparison to that of WMC0 suggests the larger mesopore size of WMC7. As calculated from the isotherms, the pore structure parameters, DFT pore size distributions and cumulative pore volume curves are shown in Table 1, Fig. $3 \mathrm{~b}$ and S1, respectively. Obviously, WMC0 and WMC7 demonstrate a mesoporedominant structure with a large mesopore proportion $\left(V_{\text {mes }} \%\right)$ of $75 \%$ and $85 \%$, respectively (Fig. S1 $\dagger$ ). The mesopore of WMC0 centers at a small size of $3.1 \mathrm{~nm}$, whereas that of WMC7 is increased to $8.6 \mathrm{~nm}$ (Fig. 3b), which is consistent with the TEM observation. The smaller mesopore size of $3.1 \mathrm{~nm}$ endows WMC0 with a much larger surface area of $1538 \mathrm{~m}^{2} \mathrm{~g}^{-1}$. For comparison, the commercial AC shows a micropore-dominant structure $\left(V_{\mathrm{mic}} \%=88 \%\right.$, Fig. S1 $\left.\dagger\right)$ with a micropore size of $1.3 \mathrm{~nm}$ and a surface area of $1471 \mathrm{~m}^{2} \mathrm{~g}^{-1}$.

This kind of large surface area primarily contributed by small mesopores combining with the 3D interconnected mesoporous structure in WMC0 will be beneficial to donating a large ion-accessible surface area for both aqueous and organic electrolyte, and providing high efficient mass transfer pathways. Thus, GCD tests of the WMCs were carried out below in both $\mathrm{KOH}$ and $\mathrm{TEABF}_{4}$ electrolyte.

According to the discharge time of the GCD curves in Fig. 4a, WMC0 presents the largest $C_{\mathrm{m}}$ of $189 \mathrm{~F} \mathrm{~g}^{-1}$ in $6 \mathrm{M} \mathrm{KOH}$. Although this value is at the medium level of the reported PCMbased electrode $\left(50-350 \mathrm{~F} \mathrm{~g}^{-1}\right),{ }^{5-26}$ its corresponding $C_{\mathrm{m}}$ in organic electrolyte of TEABF 4 is calculated to be $174 \mathrm{~F} \mathrm{~g}^{-1}$ (Fig. 4b), which is among the highest value of the other PCMs $\left(20-200 \mathrm{~F} \mathrm{~g}^{-1}\right) \cdot{ }^{28-34,41-46}$ Generally, when $\mathrm{TEABF}_{4}$ is used to substitute aqueous electrolyte, the $C_{\mathrm{m}}$ would be reduced to a great extent of $c a .25-55 \%$ because the ion size of $\mathrm{TEA}^{+} / \mathrm{BF}_{4}{ }^{-}$ $(c a .0 .6 \mathrm{~nm})$ and solvated $\mathrm{TEA}^{+} / \mathrm{BF}_{4}{ }^{-}(c a .1 .2 \mathrm{~nm})$ is much larger than that of aqueous electrolyte, ${ }^{29-34}$ leading to a sharp decrease of the ion-accessible surface area, e.g., a $C_{\mathrm{m}}$-decreased extent of $25 \%,{ }^{32} 51 \%$ (ref. 30 ) and $55 \%$ (ref. 29 ) from aqueous to $\mathrm{TEABF}_{4}$ electrolyte. It is surprising that the $C_{\mathrm{m}}$ of WMC0 and WMC7 only presents a negligible decrease in $\mathrm{TEABF}_{4}(8 \%$ and $7 \%$, respectively). In a sharp contrast, the commercial AC exhibits a large decreasing extent of $45 \%$ (from 172 to $95 \mathrm{~F} \mathrm{~g}^{-1}$ ) and this
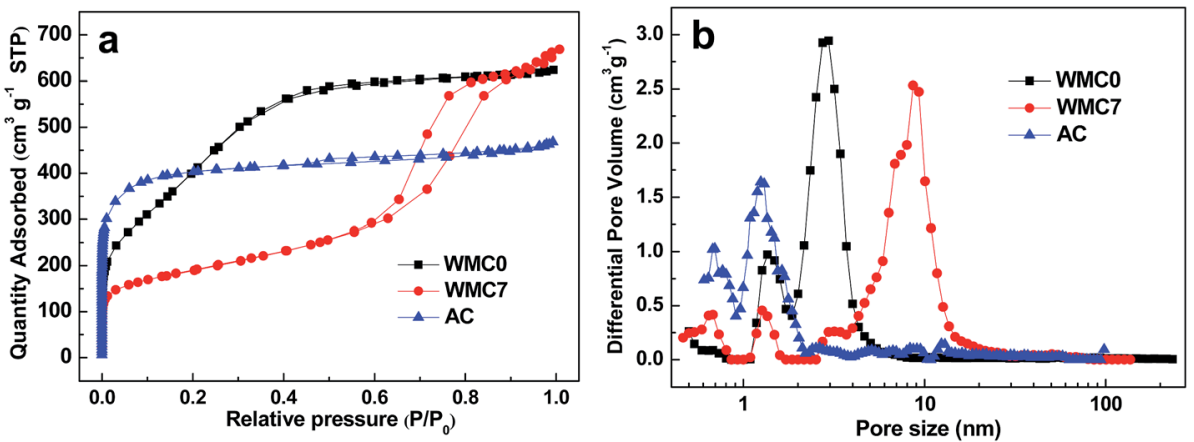

Fig. 3 (a) $\mathrm{N}_{2}$ adsorption-desorption isotherms at $77 \mathrm{~K}$ and (b) DFT pore size distribution curves of the samples. 
Table 1 Pore structure parameters of the samples

\begin{tabular}{lcllll}
\hline Sample & $\begin{array}{l}S_{\text {BET }} \\
\left(\mathrm{m}^{2} \mathrm{~g}^{-1}\right)\end{array}$ & $\begin{array}{l}V_{\text {total }} \\
\left(\mathrm{cm}^{3} \mathrm{~g}^{-1}\right)\end{array}$ & $V_{\text {mic } \%}$ & $V_{\text {mes }} \%$ & $\begin{array}{l}\text { Pore size } \\
(\mathrm{nm})\end{array}$ \\
\hline WMC0 & 1538 & 0.97 & $25 \%$ & $75 \%$ & 3.1 \\
WMC7 & 667 & 1.03 & $15 \%$ & $85 \%$ & 8.6 \\
AC & 1471 & 0.72 & $86 \%$ & $14 \%$ & 1.3
\end{tabular}

phenomenon becomes more and more serious while increasing the current density, since the solvated ion sizes of $\mathrm{TEA}^{+}$and $\mathrm{BF}_{4}{ }^{-}$are comparable to the micropore size of AC. For example, at the extremely high current density of $10 \mathrm{~A} \mathrm{~g}^{-1}$, the capacitance retention $\left(R_{\mathrm{C}}\right)$ of $\mathrm{AC}$ in $\mathrm{KOH}$ and $\mathrm{TEABF}_{4}$ is decreased to $69 \%$ and $9.5 \%$, respectively (Fig. $4 \mathrm{c}$ and d), giving rise to a $C_{\mathrm{m}}$ decrease of $92 \%$. In terms of WMC0 and WMC7, an $R_{\mathrm{C}}$ of $85 \%$ / $79 \%$ and $87 \% / 83 \%\left(161 \mathrm{~F} \mathrm{~g}^{-1} / 137 \mathrm{~F} \mathrm{~g}^{-1}\right.$ and $\left.88 \mathrm{~F} \mathrm{~g}^{-1} / 78 \mathrm{~F} \mathrm{~g}^{-1}\right)$ is obtained at $10 \mathrm{~A} \mathrm{~g}^{-1}$ in $\mathrm{KOH} / \mathrm{TEABF}_{4}$, respectively, indicating a low $C_{\mathrm{m}}$ decrease extent of $12-15 \%$. This is because the dominant pore size of WMC0 and WMC7 is almost 3 and 7 times larger than that of the solvated $\mathrm{TEA}^{+}$and $\mathrm{BF}_{4}{ }^{-}$, respectively. These results demonstrate that the mesopore-dominant nanostructure and 3D interconnected mesopore morphology endow the WMC with excellent ion-accessibility of the surface area and efficient mass transfer capability, which can be confirmed by the CV measurements and EIS tests below.

As we know, the ion diffusion behaviors within a nanoporous carbon structure can be estimated by the rectangle degree of the CV curve at a relatively high scan rate. ${ }^{18}$ It can be obviously seen that the commercial AC shows a more distorted shape of the $\mathrm{CV}$ curve in $\mathrm{TEABF}_{4}$ as compared to that in $\mathrm{KOH}$ at $100 \mathrm{mV} \mathrm{s}^{-1}$ (Fig. 5a), implying the poor ion accessibility and transfer capability of the micropores in $\mathrm{TEABF}_{4}$. Fortunately, in Fig. $5 \mathrm{~b}$ and $\mathrm{c}$, the comparable rectangle degree of the $\mathrm{CV}$ curves in WMC samples implies that the increase of the ion size in $\mathrm{TEABF}_{4}$ has much smaller influence on the ion diffusion behavior. The $C_{\mathrm{m}}$ calculated from the $\mathrm{CV}$ curves is shown in Table 2, which demonstrates a similar decreasing extent in organic electrolyte as compared to that calculated from the GCD tests at a relatively high current density of $3 \mathrm{~A} \mathrm{~g}^{-1}$.

The polarization resistance or charge transfer resistance $\left(R_{\mathrm{p}} /\right.$ $R_{\mathrm{ct}}$ ) of WMC0 and WMC7 estimated from the diameter of the semicircle in the high frequency region in Nyquist plots is 2.2 and $1.9 \Omega$ (Fig. 6a), respectively, which are much lower than that of AC $(7.2 \Omega)$. Furthermore, benefiting from the 3D carbon nanoskeleton, WMC0 and WMC7 show much lower equivalent series resistance of $c a$. 1.8 $\Omega$ compared with commercial AC ( $c a$. $4.9 \Omega$ ), which can be obtained from the initial intersection between the curve and $Z^{\prime}$ axis in Nyquist plots. ${ }^{19}$ To further demonstrate the applicability of these WMC samples in EDLC electrodes, cycling test results of 10000 cycles at $1 \mathrm{~A} \mathrm{~g} \mathrm{~g}^{-1}$ are presented in Fig. 6b. Both WMC samples show great cycling stability with a $R_{\mathrm{C}}$ of $97.7 \%$ after 10000 cycles, whereas the $R_{\mathrm{C}}$ of the commercial AC is decreased to $78 \%$.

Overall, although a large surface area of the PCM-based electrode is considered necessary for energy storage, increasing the surface area unlimitedly may result in a sharp decrease of the pore size, thus reducing the utilization of the surface area greatly, particularly in organic electrolyte with larger ion sizes. Paradoxically, an excessively large pore size will
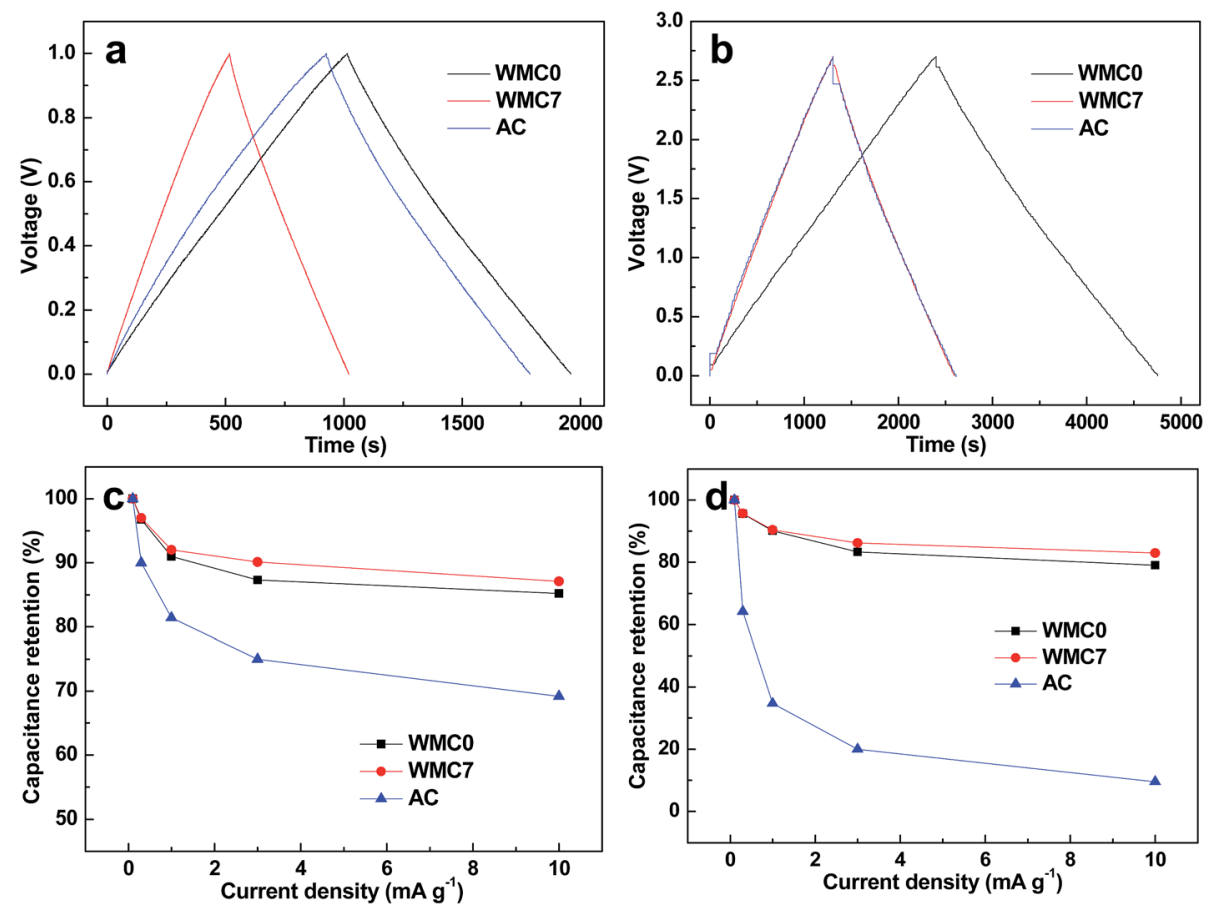

Fig. 4 GCD curves of the samples at the current density of $0.1 \mathrm{~A} \mathrm{~g}^{-1}$ in (a) $6 \mathrm{M} \mathrm{KOH}$ and (b) $1 \mathrm{M} \mathrm{TEABF}_{4}$; capacitance retention at various current densities in (c) $6 \mathrm{M} \mathrm{KOH}$ and (d) $1 \mathrm{M} \mathrm{TEABF}_{4}$. 

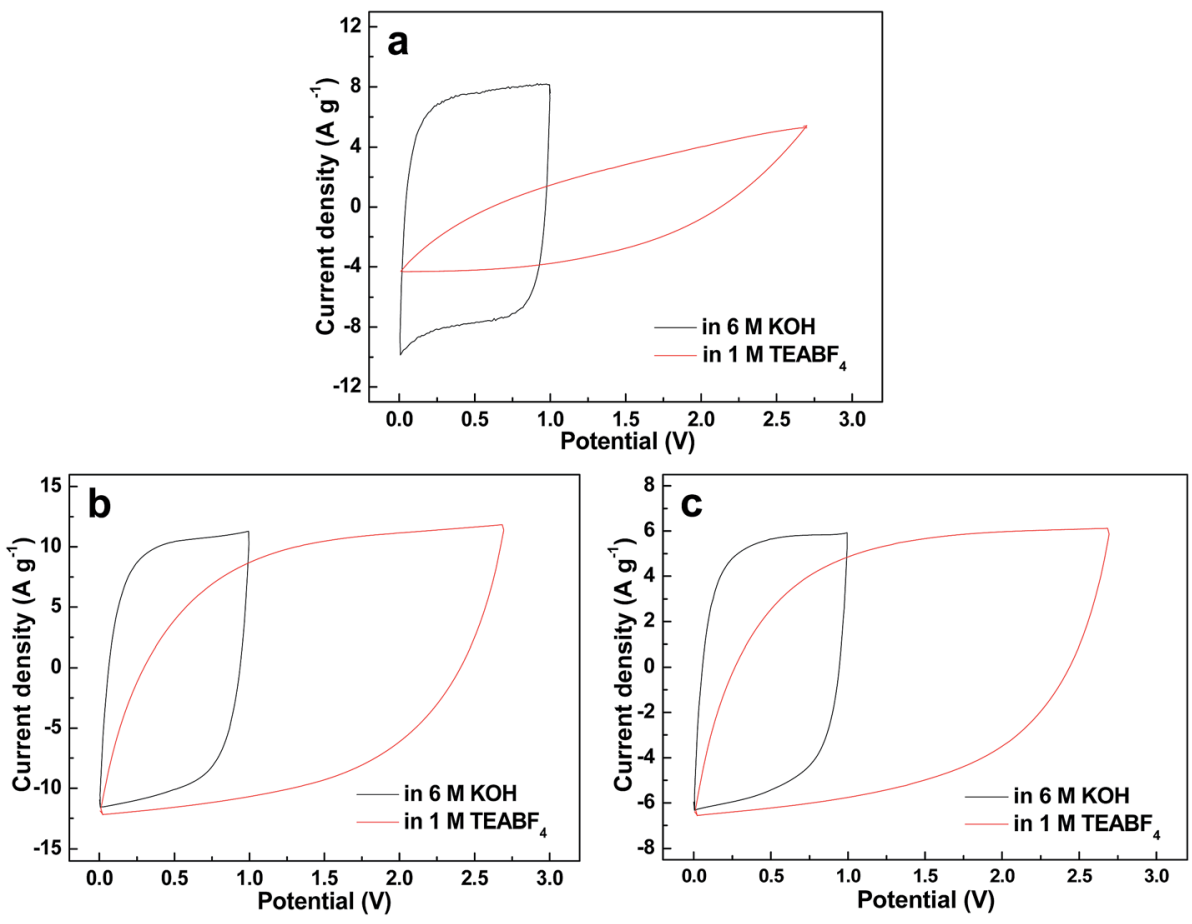

Fig. $5 \mathrm{CV}$ curves at the scan rate of $100 \mathrm{mV} \mathrm{s}^{-1}$ in $6 \mathrm{M} \mathrm{KOH}$ and $1 \mathrm{M} \mathrm{TEABF}_{4}$ of the (a) AC, (b) WMCO and (c) WMC7.

Table 2 The $C_{m}$ calculated from the GCD tests at $3 \mathrm{~A} \mathrm{~g}^{-1}$ and $\mathrm{CV}$ tests at $100 \mathrm{mV} \mathrm{s}^{-1}$

\begin{tabular}{lrrrrr}
\hline & \multicolumn{2}{c}{$C_{\mathrm{m}}$ from GCD tests $\left(\mathrm{F} \mathrm{g}^{-1}\right)$} & & \multicolumn{2}{c}{$C_{\mathrm{m}}$ from CV tests $\left(\mathrm{F} \mathrm{g}^{-1}\right)$} \\
\cline { 2 - 3 } \cline { 5 - 6 } Sample & $6 \mathrm{M} \mathrm{KOH}$ & $1 \mathrm{M} \mathrm{TEABF}_{4}$ & & $6 \mathrm{M} \mathrm{KOH}$ & $1 \mathrm{M} \mathrm{TEABF}_{4}$ \\
\hline WMC0 & 165 & 145 & 172 & 153 \\
WMC7 & 91 & 81 & 94 & 84 \\
AC & 129 & 28 & 138 & 43 \\
\end{tabular}

undoubtedly lead to a relatively low surface area, such as WMC7 in this work. Thus, constructing a developed mesopore nanostructure and moderate pore size for obtaining a high surface area with ion-accessibility is believed to demonstrate the optimal supercapacitive behaviors.

\section{Conclusions}

WMC with mesopore-dominant structure is adopted as the electrode materials of EDLCs and demonstrates superior electrochemical performance, particularly in organic electrolyte. For example, the WMC0 sample presents a $C_{\mathrm{m}}$ of $189 \mathrm{~F} \mathrm{~g}^{-1}$ in $6 \mathrm{M} \mathrm{KOH}$ and $174 \mathrm{~F} \mathrm{~g}^{-1}$ in $1 \mathrm{M} \mathrm{TEABF}_{4}$, implying a slight $C_{\mathrm{m}}$ decrease of about $8 \%$. Furthermore, a much more superior high-rate capability in $\mathrm{TEABF}_{4}$ is obtained for the WMC0 sample as compared to that of most PCMs. These excellent supercapacitive performances can be attributed to the combination effect of $3 \mathrm{D}$ continuous carbon framework, suitable mesopore size and interconnected mesopore-dominant structure. We anticipate that this study would be useful for the development of high performance supercapacitors and provide a benchmark for better designing PCMs with desired nanostructure for practical applications.
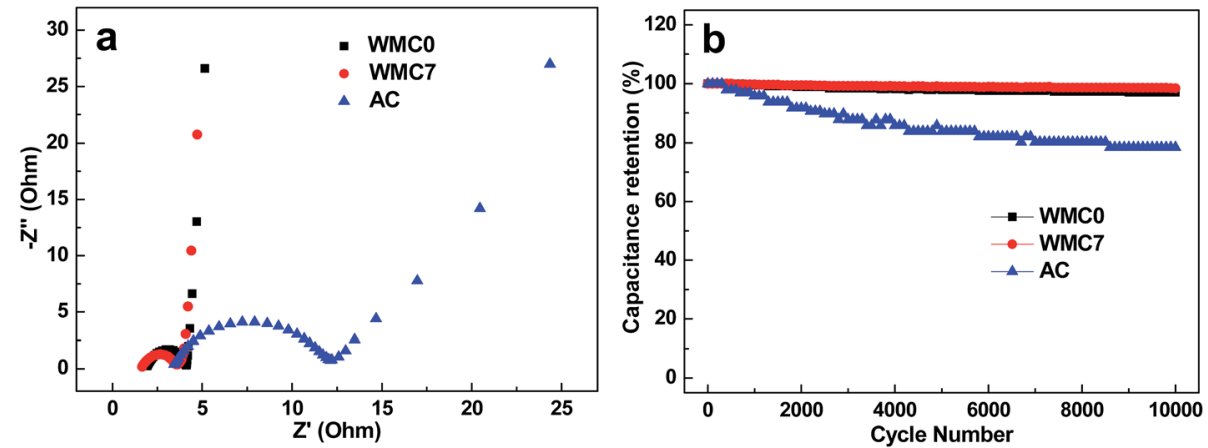

Fig. 6 (a) Nyquist plots and (b) cycling tests at the current density of $1 \mathrm{~A} \mathrm{~g}^{-1}$ in $1 \mathrm{M} \mathrm{TEABF}_{4}$ for 10000 cycles of the samples. 


\section{Acknowledgements}

This research is financially supported by The projects of NNSFC (51602061), The Start-up funding for Young talent of Guangdong University of technology (220413521), The scientific and technological project of Guangdong province, (502160192).

\section{References}

1 Q. Xie, G. Chen, R. Bao, Y. Zhang and S. Wu, Microporous Mesoporous Mater., 2017, 239, 130-137.

2 Z. Li, L. Li, Z. Li, H. Liao and H. Zhang, Electrochim. Acta, 2016, 222, 990-998.

3 W. Yang, W. Yang, F. Ding, L. Sang, Z. Ma and G. Shao, Carbon, 2017, 111, 419-427.

4 X. He, Z. Liu, H. Ma, N. Zhang, M. Yu and M. Wu, Microporous Mesoporous Mater., 2016, 236, 134-140.

5 N. Shcherban, S. Filonenko, P. Yaremov, V. Dyadyun, I. Bezverkhyy and V. Ilyin, J. Mater. Sci., 2017, 52, 1523-1533.

6 K. Huang, Y. Yao, X. Yang, Z. Chen and M. Li, Mater. Chem. Phys., 2016, 169, 1-5.

7 J. Wang and Q. Liu, RSC Adv., 2015, 5, 4396-4403.

8 C. Li, X. Yang and G. Zhang, Mater. Lett., 2015, 161, 538-541.

9 J. Liu, X. Wang, J. Gao, Y. Zhang, Q. Lu and M. Liu, Electrochim. Acta, 2016, 211, 183-192.

10 L. Zhang, T. You, T. Zhou, X. Zhou and F. Xu, ACS Appl. Mater. Interfaces, 2016, 8, 13918-13925.

11 G. Ma, F. Hua, K. Sun, Z. Zhang, E. Feng, H. Peng and Z. Lei, RSC Adv., 2016, 6, 103508-103516.

12 A. Chen, Y. Yu, Y. Li, Y. Wang, Y. Li, S. Li and K. Xia, J. Mater. Sci., 2016, 51, 4601-4608.

13 Y. Liang, Z. Li, R. Fu and D. Wu, J. Mater. Chem. A, 2013, 1, 3768-3773.

14 X. Yang, C. Li and Y. Chen, J. Phys. D: Appl. Phys., 2017, 50, 055501.

15 R. R. Rajagopal, L. S. Aravinda, R. Rajarao, B. R. Bhat and V. Sahajwalla, Electrochim. Acta, 2016, 211, 488-498.

16 W. Lu, M. Liu, L. Miao, D. Zhu, X. Wang, H. Duan, Z. Wang, L. Li, Z. Xu, L. Gan and L. Chen, Electrochim. Acta, 2016, 205, 132-141.

17 Y. Liang, F. Liang, H. Zhong, Z. Li, R. Fu and D. Wu, J. Mater. Chem. A, 2013, 1, 7000-7005.

18 F. Xu, R. Cai, Q. Zeng, C. Zou, D. Wu, F. Li, X. Lu, Y. Liang and R. Fu, J. Mater. Chem., 2011, 21, 1970-1976.

19 Y. Zhao, W. Ran, J. He, Y. Song, C. Zhang, D.-B. Xiong, F. Gao, J. Wu and Y. Xia, ACS Appl. Mater. Interfaces, 2015, 7, 1132-1139.

20 Y. Zhao, Z. Zhang, Y. Ren, W. Ran, X. Chen, J. Wu and F. Gao, J. Power Sources, 2015, 286, 1-9.

21 F. Xu, Z. Tang, S. Huang, L. Chen, Y. Liang, W. Mai, H. Zhong, R. Fu and D. Wu, Nat. Commun., 2015, 6, 7221.
22 L. L. Zhang and X. S. Zhao, Chem. Soc. Rev., 2009, 38, 25202531.

23 S. Bose, T. Kuila, A. K. Mishra, R. Rajasekar, N. H. Kim and J. H. Lee, J. Mater. Chem., 2012, 22, 767-784.

24 A. Izadi-Najafabadi, S. Yasuda, K. Kobashi, T. Yamada, D. N. Futaba, H. Hatori, M. Yumura, S. Iijima and K. Hata, Adv. Mater., 2010, 22, E235-E241.

25 Shilpa and A. Sharma, RSC Adv., 2016, 6, 78528-78537.

26 X. Yang, C. Li and R. Fu, J. Power Sources, 2016, 319, 6672.

27 X. Yang, G. Zhang, M. Zhong, D. Wu and R. Fu, Langmuir, 2014, 30, 9183-9189.

28 J. Chmiola, C. Largeot, P.-L. Taberna, P. Simon and Y. Gogotsi, Angew. Chem., Int. Ed., 2008, 47, 3392-3395.

29 D. Wang, Y. Min and Y. Yu, J. Solid State Electrochem., 2015, 19, 577-584.

30 C. Zheng, X. Zhou, H. Cao, G. Wang and Z. Liu, J. Power Sources, 2014, 258, 290-296.

31 Y. Li, Z. Li and P. K. Shen, Adv. Mater., 2013, 25, 2474-2480. 32 J. A. Fernandez, M. Arulepp, J. Leis, F. Stoeckli and T. A. Centeno, Electrochim. Acta, 2008, 53, 7111-7116.

33 C. Ma, Y. Li, J. Shi, Y. Song and L. Liu, Chem. Eng. J., 2014, 249, 216-225.

34 J. Xu, Q. Gao, Y. Zhang, Y. Tan, W. Tian, L. Zhu and L. Jiang, Sci. Rep., 2014, 4, 5545.

35 T. Chau and V. Kalra, J. Power Sources, 2013, 235, 289-296.

36 L.-B. Xing, J.-L. Zhang, J. Zhang, S.-F. Hou, J. Zhou, W. Si, H. Cui and S. Zhuo, Electrochim. Acta, 2015, 176, 1288-1295.

37 D. Wu, Z. Li, Y. Liang, X. Yang, X. Zeng and R. Fu, Carbon, 2009, 47, 916-918.

38 X. Yang, C. Wei and G. Zhang, J. Mater. Sci., 2016, 51, 55655571.

39 Y. Zhao, M. Liu, X. Deng, L. Miao, P. K. Tripathi, X. Ma, D. Zhu, Z. Xu, Z. Hao and L. Gan, Electrochim. Acta, 2015, 153, 448-455.

40 E. J. A. Pope and J. D. Mackenzie, J. Non-Cryst. Solids, 1986, 87, 185-198.

41 G. Sun, W. Song, X. Liu, D. Long, W. Qiao and L. Ling, Electrochim. Acta, 2011, 56, 9248-9256.

42 H. Zhou, Y. Peng, H. B. Wu, F. Sun, H. Yu, F. Liu, Q. Xu and Y. Lu, Nano Energy, 2016, 21, 80-89.

43 D. Bhattacharjya, M.-S. Kim, T.-S. Bae and J.-S. Yu, J. Power Sources, 2013, 244, 799-805.

44 R. R. Salunkhe, C. Young, J. Tang, T. Takei, Y. Ide, N. Kobayashi and Y. Yamauchi, Chem. Commun., 2016, 52, 4764-4767.

45 F. Markoulidis, C. Lei, C. Lekakou, D. Duff, S. Khalil, B. Martorana and I. Cannavaro, Carbon, 2014, 68, 58-66.

46 B. Li, F. Dai, Q. Xiao, L. Yang, J. Shen, C. Zhang and M. Cai, Energy Environ. Sci., 2016, 9, 102-106. 